\title{
Linhas paralelas: as distintas aproximações da Psicologia em relação ao trabalho
}

\author{
Parallel lines: Different ways by which \\ Psychology has approached work
}

\author{
Marcia Hespanhol BERNARDO \\ Fábio de OLIVEIRA ${ }^{2}$ \\ Heloisa Aparecida de SOUZA ${ }^{1}$ \\ Caroline Cristiane de SOUSA ${ }^{1}$
}

\begin{abstract}
Resumo
Este artigo analisa diferentes aproximações da Psicologia em relação ao mundo do trabalho, trazendo elementos para o debate sobre a unicidade, ou não, das abordagens construídas ao longo da história dessas aproximaç̃̃es, com foco nas vertentes da Psicologia Social do Trabalho e da Psicologia Organizacional. Para tanto, buscou-se compreender a história dessas tradições, suas origens e seu lugar no contexto contemporâneo. Concluiu-se que elas possuem diferentes abordagens e compreensões sobre o mundo do trabalho, com poucos pontos em comum em seus processos históricos e em suas expressões atuais, o que sinaliza a impossibilidade de afirmação de um campo unitário. A importância de demarcar essas fronteiras entre as diferentes vertentes da Psicologia que focalizam o trabalho é possibilitar a identificação das especificidades de cada uma, bem como apontar a diversidade de objetos de estudo, referenciais teóricos, propostas metodológicas e posicionamentos políticos que envolvem as pesquisas ou as intervenções.
\end{abstract}

Palavras-chave: Discurso gerencial; Psicologia crítica; Psicologia organizacional; Psicologia social; Trabalho.

\begin{abstract}
This article analyses different ways by which Psychology has approached the world of work, promoting debate on whether these strategies constitute a unique or unified approach. Focusing on the branches Social Psychology of Work and Organizational Psychology, we aimed at understanding the history of these two traditions, their origins, and their role in the contemporary context. It was concluded that they have different approaches and understandings of the world of work, and that their historical processes, as well as their representation today, have very little in common. This indicates that they do not belong to the same field. Establishing boundaries between different approaches of Psychology that focus on work, enables the identification of their specificities and reveals the diversity of their objects of study, theoretical framework, methodological proposals, and the political aspects involved in their studies or interventions.
\end{abstract}

Keywords: Managerial discourse; Critical psychology; Organizational psychology; Social psychology; Work.

\footnotetext{
$\nabla \nabla v$

1 Pontifícia Universidade Católica de Campinas, Centro de Ciências da Vida, Programa de Pós-Graduação em Psicologia. Av. Jonh Boyd Dunlop, s/n., 13060-904, Jardim Ipassurama, Campinas, SP, Brasil. Correspondência para/Correspondence to: M.H. BERNARDO. E-mail: <marciahespanhol@hotmail.com>.

2 Universidade de São Paulo, Instituto de Psicologia, Departamento de Psicologia Social e do Trabalho. São Paulo, SP, Brasil.
} 
Atualmente, no Brasil, podem-se identificar posições diversificadas em relação ao trabalho humano como objeto da Psicologia. Frequentemente, essas posições são apresentadas como nuances de uma única área, que costuma ser denominada, nos campos acadêmico e profissional, como 'Psicologia Organizacional e do Trabalho'.

Todavia, considera-se que existem enfoques que tomam o trabalho como objetos de pesquisas e de intervenções, por vezes, tão diversos que fazem com que esse agrupamento sob uma designação única seja artificial e dificulte a identificação das especificidades de cada uma das abordagens. Isso tem consequências importantes, pois, segundo Lhuilier (2014, p.5), "dependendo do sentido e do alcance dados a essa noção polissêmica de 'trabalho', perfilam-se concepções contrastantes de homem e sociedade, associadas a escolhas ao mesmo tempo filosóficas e políticas".

Partindo desse pressuposto, busca-se apresentar a seguir algumas diferenças entre duas perspectivas específicas predominantes no Brasil com o intuito de destacar as características de cada uma e, assim, contribuir para o debate sobre as distintas aproximações da Psicologia, enquanto ciência e profissão, com o mundo do trabalho.

Este estudo propõe que é fundamental tratar essas diferentes abordagens não como pontos de vista complementares sobre um mesmo objeto, mas como tradições que, historicamente, construíram objetos diferentes e que são, de certo modo, irredutíveis uns aos outros. Trata-se de compreender como cada tradição se constituiu a partir dos problemas que elegeu enfrentar, dos compromissos que assumiu e dos horizontes de possibilidades (e impossibilidades) que se abrem a partir daí, isto é, suas diferenças teóricas, metodológicas e ético-políticas.

Certamente, as possibilidades de aproximação da Psicologia com o trabalho são muitas. Mas, aqui, optou-se por abordar, especificamente, duas tradições - a 'Psicologia Organizacional' e a 'Psicologia Social do Trabalho' -, tendo em vista que ambas se ocupam de aspectos sociais do trabalho e se destacam na produção científica nacional e nos debates a respeito da atuação profissional do
Ainda que, internamente, cada uma delas inclua certa diversidade temática e teórico-metodológica, o texto que segue busca apresentar alguns aspectos históricos relevantes que ajudaram a conformar essas tradições até suas características atuais, podendo ser útil para que elas se desenvolvam e cumpram seus propósitos de forma autêntica e autônoma.

A escolha desse caminho tem como referência as proposições de Kuhn (1987) a respeito da ciência. De acordo com o autor, o que define uma área científica é sua história e sua prática efetiva, e não regras definidas a priori, como defendem algumas perspectivas filosóficas, especialmente a do positivismo. Assim, apesar de o conceito de paradigma ser o aspecto mais conhecido de seus escritos, a importância atribuída à história da ciência, também uma das principais contribuições desse filósofo, justifica a presente opção.

No caso da Psicologia, segundo afirma Smith (1988), "é notório" que ela não tem "um corpo unificado de conhecimentos com um núcleo comum de conceitos mutuamente consistentes" (p.154), que poderia ser definido como 'um' paradigma. $\mathrm{Na}$ verdade, essa ciência se caracteriza por ser um conjunto de paradigmas, e o que possibilita compreender esse conjunto é sua história. Latour e Woolgar (1997) destacam, ainda, a importância de se avaliar conjuntamente o conteúdo científico e como ele é produzido, tendo em vista que existe uma marca do contexto sobre o que é apresentado como resultado de um trabalho científico.

Assim, as diferenças entre as diversas 'psicologias' abrangem seus objetos, fundamentações teóricas, práticas, bem como suas concepções sobre o que é ciência e, no presente caso, sobre a tessitura social na qual se dá o trabalho humano na atualidade. Disso deriva que, para entender as relações da Psicologia com o campo do trabalho, seja no âmbito da pesquisa ou da intervenção, é fundamental a compreensão da história de como se construíram essas relações, bem como o olhar para o que efetivamente se faz hoje, seja com relação à produção teórica ou à prática profissional. Todavia, tendo em vista que essa empreitada não pode ser apresentada integralmente no espaço de um artigo, 
optou-se aqui por enfatizar a mirada para a história das duas abordagens focalizadas, trazendo apenas alguns elementos do contexto atual que demonstram como essas tradições ainda permanecem fiéis ao seu desenvolvimento histórico, ainda que, por vezes, de forma menos explícita.

\section{Trajetórias das diferentes aproximações da Psicologia com o Trabalho}

Sem ter a pretensão de apresentar 'a' história da relação da Psicologia com o Trabalho, foram selecionados alguns elementos relevantes que ajudam a compreender como, historicamente, as formas como cada um desses enfoques se relacionou com o trabalho, com os trabalhadores e com as gerências demarcam características suficientemente distintas que impossibilitam considerá-los como uma única área.

\section{As raízes da Psicologia Organizacional desenvolvida no Brasil: a aproximação com as demandas gerenciais}

Ainda que o foco deste estudo seja o contexto brasileiro, entende-se que a Psicologia Organizacional desenvolvida no país tem sua história estreitamente relacionada com a literatura internacional. É por isso que se inicia com uma apresentação mais geral.

Há um consenso (Braverman, 1987; Malvezzi, 1999; Spink,1996; Zanelli \& Bastos, 2004) de que o primeiro psicólogo a escrever sistematicamente sobre o tema trabalho foi Hugo Münstenberg. Seu livro intitulado "Psicologia e eficiência industrial" costuma ser considerado "o primeiro esboço sistemático da Psicologia Industrial" (Braverman, 1987, p.126).

Esse livro foi lançado na Alemanha em 1912 e publicado em inglês no ano seguinte (Braverman, 1987), momento em que a concepção positivista dominava o campo científico e a economia capitalista, baseada na produção em série nas grandes fábricas, estava em franca expansão. Foi esse contexto que possibilitou que Münstenberg afirmasse sem constrangimentos que seu objetivo era "traçar os esboços de uma nova ciência" que fosse "intermediária entre o moderno laboratório de Psicologia e os problemas da Economia", argumentando que "a experimentação psicológica deve ser sistematicamente colocada a serviço do comércio e da indústria" (Braverman, 1987, p.126, grifo nosso). Bem ao espírito que imperava em sua época, Münstenberg buscava utilizar técnicas experimentais que possibilitavam à Psicologia atribuir-se o status de ciência. O autor partia do princípio de que a industrialização seria a "alavanca de desenvolvimento econômico e social" e, de acordo com Spink (1996), ele não levava em conta as consequências que esse desenvolvimento poderia trazer para a sociedade e tampouco questionava as relações sociais que produzia.

Suas primeiras publicações focalizavam justamente a seleção de pessoal e indicavam com clareza qual era o propósito dessa nova atividade da Psicologia científica. O argumento era que o psicólogo teria um papel relevante tanto para o empregador, como para o empregado, ao encontrar o lugar mais adequado às capacidades de cada trabalhador. Spink (1996) ressalta que, nesse tipo de entendimento da sociedade, não se colocavam problemas éticos para a atuação do psicólogo, pois "qualquer possível tensão entre os valores do psicólogo e o novo campo em expansão foi aliviada por uma ideologia profissional e gerencial voltada à importância da satisfação pessoal para o indivíduo alocado num posto de trabalho que seria o melhor para suas habilidades" (p.179).

Münstenberg abriu, assim, um novo campo de atuação para a Psicologia junto às gerências. E, vale dizer, ainda nos tempos atuais, a seleção de pessoal é uma das principais atividades exercidas pela Psicologia Organizacional. Malvezzi (1999) também afirma que a história da inserção da Psicologia no campo do trabalho "revela uma trajetória de interdependência com as necessidades, valores e expectativas do processo de industrialização" (p.313). E pode-se acrescentar que, tendo sua origem no período de expansão industrial, ela nasce com o propósito de atender às necessidades colocadas por tal setor. Por isso, a denominação desse 
enfoque que predominou por décadas em diversos países foi "Psicologia Industrial" (Sampaio, 1998).

Posteriormente, a inserção da Psicologia no campo do trabalho ampliou-se, mas manteve a proximidade com a perspectiva gerencial. Os famosos e polêmicos experimentos de Elton Mayo, realizados na década de 1920, compõem um dos elementos históricos mais determinantes para essa ampliação. A partir deles, a Psicologia começava a incluir as relações interpessoais no local de trabalho entre seus objetos de interesse, filiando-se à chamada "Escola de Relações Humanas". É relevante destacar que o discurso de Mayo era o de que buscava recuperar o lado humano e social do trabalho, perdido com o tecnicismo e o individualismo dos modelos de organização do trabalho predominantes na época. Ele salientava a importância dos sentimentos e das relações humanas dos trabalhadores entre si e com os gerentes.

Mas essa "humanização" desconsiderava os efeitos da atividade laboral propriamente dita sobre os trabalhadores. A proposta era, basicamente, aplicar técnicas que promovessem relações sociais mais amigáveis no local de trabalho, elevando a "motivação dos assalariados" (Seligmann-Silva, 2011), sem mudar o ambiente material ou a organização dos processos de trabalho. Por isso, essa abordagem sofreu e vem sofrendo severas críticas. Prilleltensky (1994), por exemplo, afirma que Mayo tinha "a convicção de que relações humanas cooperativas entre trabalhadores e empresários eram a chave para a produtividade e a tranquilidade industrial" (p.132). Assim, "promoveu a técnica através da qual os administradores seriam capazes de conquistar a confiança dos trabalhadores e prevenir os conflitos nas indústrias" (p.132).

Seligmann-Silva (2011) ressalta que, apesar de ser diferente na aparência, essa proposta apenas complementa os princípios de organização da produção fundamentados no taylorismo e o modelo de seleção de pessoal de Münstenberg. Enquanto estes traçam "o caminho da disciplinarização planejada, a psicossociologia, que se apoia nas ideias de Mayo e seus seguidores, procura garantir a suavização e a dissimulação das coerções embutidas nas

18 formas de gerenciar e estruturar a organização do trabalho" (p.37). Em uma perspectiva semelhante, Huczynski (1993) conclui que a Escola de Relações Humanas, fundada por Mayo, representa, na verdade, apenas "uma mudança nas táticas gerenciais em vez de alguma transformação fundamental nos objetivos" do trabalho (p.16).

Assim, se Münstenberg teve grande influência no desenvolvimento inicial da Psicologia que, até os dias atuais, se ocupa da seleção de pessoal, as ideias de Mayo fundamentaram várias correntes que se desenvolveram posteriormente com foco nas relações interpessoais no trabalho, permitindo ampliar consideravelmente as possibilidades de atuação de psicólogos junto à gestão de empresas. Huczynski (1993) cita autores proeminentes, tais como Maslow, Likert e Argyris, como exemplos dessa influência e os inclui em uma mesma corrente descendente das ideias de Mayo, que denomina Neo-Human Relations. Essa trajetória indica que, em tal perspectiva, não caberiam ao psicólogo muitos questionamentos sobre as relações de trabalho para além das dinâmicas grupais tomadas em si mesmas. O contexto social mais amplo em que elas ocorrem, por sua vez, acaba sendo tratado "quase como um fenômeno natural" (Bernardo, Sousa, Pinzón, \& Souza, 2015) e, portanto, não passível de intervenção.

Esse breve apanhado histórico mostra que a relação dessa vertente da Psicologia com o mundo do trabalho nasceu e se consolidou pela sua prática vinculada às necessidades gerenciais de cada época, "trabalhando a partir do pressuposto de que estão simplesmente oferecendo um serviço apolítico que irá atingir favoravelmente proprietários e trabalhadores por igual" (Prilleltensky, 1994, p.148).

Parece não haver dúvidas de que tais características foram decisivas na conformação da Psicologia Organizacional tal qual é conhecida hoje. Não se pode afirmar que ela seja a mesma desde a sua origem, pois, certamente, em mais de um século de existência, ocorreram inúmeras transformações e adaptações em suas práticas e concepções. $\mathrm{Na}$ atualidade, observa-se a inclusão de outros temas, tais como qualidade de vida no trabalho, clima organizacional, cultura organizacional, liderança, equipes de trabalho, análise de competências, 
empreendedorismo (Bendassolli, Borges-Andrade, \& Malvezzi, 2010; Zanelli, 2002). Também vale destacar que a ideia de 'organizações' é utilizada para indicar que o foco não é mais apenas a empresa privada (Associação Brasileira de Psicologia Organizacional e do Trabalho, 2009; Zanelli, 2002, p.26), mas diferentes "formatos organizacionais" (Silva, 2008, p.22), construídos por meio do compartilhamento de valores e visões de mundo a fim de orientar o comportamento no contexto de trabalho. Apesar dessa ampliação do foco, parece persistir o alinhamento com a gerência, ainda que tal proximidade não seja mais explicitada de forma tão direta como o fez Münstenberg.

Com relação ao contexto brasileiro, o que se nota é que a Psicologia Organizacional produzida mantém uma proximidade com o que é realizado em outros países, especialmente os de língua inglesa, o que se pode observar em livros de referência da área, como Zanelli, Borges-Andrade e Bastos (2007) e Borges e Mourão (2013), bem como em artigos publicados em revistas brasileiras de Psicologia.

É importante destacar que, em um manifesto publicado no sitio eletrônico da Sociedade Brasileira de Psicologia Organizacional e do Trabalho intitulado "Psicologia do trabalho e das organizações: não atuamos pela cisão", é afirmado que "aqueles que atuam com tais objetos [os da Psicologia Organizacional], por serem historicamente alvos de críticas, talvez sejam os que mais incorporaram tais críticas, aproveitando-as de modo frutífero para repensar seus princípios, valores, teorias e métodos" (Associação Brasileira de Psicologia Organizacional e do Trabalho, 2009, p.1). Esse esforço para repensar a área a partir das críticas pode ser encontrado, por exemplo, em Bastos, Yamamoto e Rodrigues (2013). Também não é incomum que artigos e livros dessa vertente partam, inclusive, de uma crítica com relação ao modelo social vigente. A recorrente referência a aspectos psicossociais do trabalho ou à qualidade de vida dos trabalhadores parece também evidenciar essa mudança discursiva.

Entretanto, o que se vê é que ainda predomina a ideia de neutralidade do psicólogo - criticada por autores como, por exemplo, Prilleltensky (1994) -, e o objetivo de fornecer ferramentas de gerência, sem envolver mudanças nas metas produtivas, no ritmo de trabalho ou no modelo técnico do processo produtivo e, muito menos, na assimetria de poder entre trabalhadores e gerência (Padilha, 2010). Assim, a modificação discursiva observada não parece refletir uma transformação essencial nos pressupostos que caracterizaram a Psicologia Organizacional ao longo de sua história, com práticas e produções teóricas essencialmente vinculadas à gestão.

As raízes da Psicologia Social do Trabalho: a aproximação com os movimentos de trabalhadores

Se, no apanhado histórico da Psicologia Organizacional sintetizado acima, partiu-se do contexto internacional, aqui, o foco é essencialmente - Brasil. Deve-se assinalar que a Psicologia Social do Trabalho desenvolveu-se em um período bem mais recente e assumiu características marcadamente locais no país. Apesar disso, sua história está em consonância com um movimento mais geral e internacional da Psicologia Social, sobretudo aquela desenvolvida na América Latina.

Inicialmente, deve-se dizer que apenas a denominação Psicologia Social do Trabalho (vale sinalizar que outra denominação também em uso, 'Psicologia Social Crítica do Trabalho', seria igualmente adequada) não é suficiente para definir o enfoque discutido neste artigo, tendo em vista que a Psicologia Social também se caracteriza pela diversidade de perspectivas epistemológicas e políticas, além de não se configurar como um ramo da Psicologia que tenha um campo claramente delimitado para a prática profissional (Montero, 2011). Ainda, a própria Psicologia Organizacional, em muitos casos, apoia-se decisivamente em certas tradições epistemológicas da Psicologia Social, como mostram Bendassolli et al. (2010).

No entanto, o presente estudo mantém a denominação Psicologia Social do Trabalho para marcar a ênfase dessa vertente no não-individualismo e para expressar um convite de retorno à Psicologia Social de caráter mais crítico, não alinha- 
da às demandas gerenciais. Cabe, então, apresentar aspectos relevantes dessa história com vistas a delimitá-la, iniciando-a com a própria Psicologia Social.

Farr (2004) lembra que, historicamente, as primeiras publicações identificadas como Psicologia Social também datam do período em que o positivismo era hegemônico. Sua história, especialmente, nos Estados Unidos, é marcada por estudos experimentais voltados para mudanças de atitudes, contribuindo para o desenvolvimento de mecanismos de controle sobre grupos humanos.

Contudo, nas décadas de 1960 e 1970, em diversos países, passou a haver um questionamento mais enfático desse referencial teórico-metodológico e uma aproximação da Psicologia Social a enfoques sociológicos críticos com relação ao sistema social vigente e suas iniquidades. Nesse período, congressos realizados por órgãos de representação da Psicologia Social na América Latina consolidaram-se como espaços de discussão sobre a possibilidade de uma Psicologia Social voltada para as condições específicas dos países latino-americanos (Montero, 2011). Assim, conquista-se o reconhecimento do caráter político das práticas psicológicas a partir do desenvolvimento de uma Psicologia Social "Crítica". De acordo com Montero (2011),

a Psicologia Social Crítica teve seu início no fim dos anos 60, quando alguns psicólogos sociais na Europa e EUA buscavam produzir formas de conhecer e interpretar a sociedade que permitissem trabalhar de maneira efetiva sobre os problemas que a afligiam. Foi também quando, na América Latina, começava a existir um inconformismo com uma psicologia acadêmica incapaz não só de solucionar problemas sociais, mas até mesmo de reconhecê-los como objeto de estudo. Nesse período, a obra transformadora e crítica de Paulo Freire, assim como os trabalhos inovadores da Sociologia Crítica, já faziam sentir suas conquistas (p.90).

Portanto, a construção da identidade política dos psicólogos sociais latino-americanos foi atra20 sionada pela contestação da situação de opressão sofrida pelos povos da região (Lima, Ciampa, \& Almeida, 2009).

Já no Brasil, a Psicologia Social teve origem a partir da vertente americana. Entretanto, segundo Lima (2010), posteriormente, ela sofreu influência das correntes contra-hegemônicas, por meio das quais foi possível elaborar propostas diferenciadas que levaram ao desenvolvimento de uma Psicologia Social Crítica também aqui.

Essas breves considerações esclarecem a perspectiva a partir da qual se constrói a Psicologia Social do Trabalho no Brasil. Ela se desenvolveu orientada por uma Psicologia Social de cunho sociológico, que propõe a reflexão acerca das consequências políticas de sua produção acadêmica, bem como das intervenções realizadas pelos profissionais.

Sato (2010) lembra que, já na década de 1970, é possível identificar estudos que utilizam um enfoque semelhante para analisar o trabalho. Eles foram realizados por psicólogos sociais que não eram "especialistas" nessa temática, mas que assumiam uma análise crítica das questões sociais e tinham os problemas humanos no trabalho entre seus objetos de investigação. Trata-se de estudos importantes, no âmbito da Psicologia, que focalizaram o universo social, os valores, as trajetórias e as aspirações de trabalhadores das classes populares, em ambos os gêneros. A autora destaca trabalhos como os de Carvalho (1981), com operários, de Mello (1988), com empregadas domésticas, e de Rodrigues (1978), com operários e funcionários públicos, que focalizam a vivência de trabalho e a condição de trabalhadores na sociedade hierarquizada. Entre as referências mais importantes que consolidam as bases históricas da Psicologia Social do Trabalho, também estão os diversos estudos empreendidos por Peter Spink, desde a década de 1970, sobre aspectos psicossociais que envolvem o trabalho. Esses estudos abordam o trabalho como um fenômeno genuinamente psicossocial, e seus objetos de pesquisa não derivam dos problemas apresentados aos gestores em sua prática. Talvez por isso, a maior parte desses autores tenham se 
mantido afastados das denominações de Psicologia Organizacional/Industrial ou mesmo de Psicologia do Trabalho.

É a partir do final da década de 1980, após a chamada crise da Psicologia Social (Montero, 2011), das intensas críticas à Psicologia Organizacional (Figueiredo, 1989) e da consolidação dos campos da Saúde do Trabalhador (Sato, Lacaz, \& Bernardo, 2006) e da Economia Solidária (Oliveira, Esteves, Bernardo, \& Sato, 2015) no Brasil, que estudos críticos de psicólogos sociais sobre o trabalho passam a ter uma expressividade numérica. Em 1998, por exemplo, começou a ser editado um periódico específico, denominado "Cadernos de Psicologia Social do Trabalho". Em seu primeiro editorial, afirma-se que, para compreender e equacionar os problemas presentes no mundo do trabalho,

... é necessário recorrer a uma Psicologia que incorpore questões relativas à constituição dos sujeitos sociais, a partir de uma compreensão que permita reconhecer o papel do contexto na conformação de relações, de visões de mundo, de criação de estratégias e táticas que fazem os "modos de andar a vida", como nos fala Canguilhem (Sato \& Oliveira, 1998, p.VII).

É interessante observar que, da mesma forma como ocorreu com a Psicologia Organizacional, a intervenção e a pesquisa também mantiveram uma relação intrínseca ao longo da história da Psicologia Social do Trabalho. No entanto, se aquela nasceu como uma prática profissional em um momento de intensificação da industrialização e intimamente ligada às demandas colocadas pela gestão de empresas, a Psicologia Social do Trabalho tem sua origem em um momento histórico de abertura política no Brasil, quando os preceitos capitalistas passam a ser fortemente criticados. Desse modo,

os pesquisadores conheceram o trabalho a partir do olhar e das vivências dos trabalhadores e se envolveram nas lutas destes últimos, seja no enfrentamento do desemprego, na negociação em prol da saúde dos trabalhadores ou na tentativa de viabilização da autogestão (Oliveira et al., 2015).
Em síntese, é possível dizer que uma das características do desenvolvimento histórico do enfoque da Psicologia Social do Trabalho é que ela sempre buscou tomar o trabalho como um fenômeno psicossocial, encarado de modo crítico, complexo e determinado pelas relações de poder que configuram o contexto social mais amplo. Desse modo, os pesquisadores e profissionais que adotam essa perspectiva assumem como base o caráter histórico, heterogêneo, contraditório e conflituoso da relação capital-trabalho, entendendo que, com esse posicionamento, dificilmente seria possível atuar ao lado da gerência (Bernardo et al., 2015). As intervenções a partir desse enfoque têm sido, então, direcionadas a contribuir com a transformação das condições de exploração dos trabalhadores em campos de atuação bastante diferentes das empresas tradicionais, tais como sindicatos, associações, cooperativas populares, empresas autogestionárias, os serviços de saúde do trabalhador na saúde pública etc. (Bernardo et al., 2015). Também vale destacar que algumas formas de inserção dos indivíduos no trabalho pouco abordadas pela Psicologia Organizacional são caras à Psicologia Social do Trabalho, como o desemprego, o trabalho informal e o trabalho rural.

Com relação ao contexto mais recente, pode-se observar, nos últimos anos, um crescente número de publicações em revistas de Psicologia que assumem essa perspectiva. Seu foco, em geral, são os processos de subjetivação de trabalhadores em variados contextos, partindo da análise do cotidiano e da perspectiva dos próprios sujeitos, tomando como pano de fundo a assimetria de poder no campo do trabalho, bem como as práticas de resistências dos trabalhadores. Observa-se que, com frequência, tais publicações não se furtam a criticar fortemente os modelos gerenciais predominantes na atualidade, relacionando-os com as características e os interesses do capitalismo. Muitos também discutem a necessidade de mudanças estruturais na sociedade visando à superação da relação desigual entre capital e trabalho. Tais estudos estão, assim, em consonância com a afirmação de Gardiner (2000), que, ao destacar a importância de se observar o cotidiano nos estudos sociais, lembra que é preciso se preocupar em analisar "as relações de 
poder assimétricas que existem entre um dado sistema burocrático ou institucional e seus usos" (p.7).

\section{Por que linhas paralelas, afinal?}

O já citado manifesto da Associação Brasileira de Psicologia Organizacional e do Trabalho (2009) visava argumentar em favor da compreensão do conjunto de todos os enfoques da Psicologia que têm como objeto o trabalho como sendo uma única área do conhecimento ou campo de atuação. Entretanto, neste ensaio, buscou-se mostrar que existem, pelo menos, duas abordagens da Psicologia que se constituíram historicamente em linhas paralelas e assim se mantêm até a atualidade.

Apesar de tanto a Psicologia Organizacional como a Psicologia Social do Trabalho não serem internamente homogêneas, o processo histórico de constituição de cada uma delas, bem como sua expressão atual, permitem identificar poucos pontos em comum entre ambas. Basicamente, compartilham apenas o fato vago de focalizarem alguma dimensão da existência humana no trabalho em suas pesquisas e intervenções. Já os objetos, problemas, compromissos e horizontes de possibilidades apontam abordagens muito distintas.

Pode-se indagar, então, como identificar quando se trata de um ou outro enfoque. Montero (2011), ao apresentar a Psicologia Social Crítica latino-americana, ajuda a pensar em respostas. Ela afirma que uma maneira de identificar se uma perspectiva da Psicologia pode ser classificada como "crítica" ou não "é destacar quais são os aspectos que constituíram sua preocupação e para os quais dirigiu suas ações" (p.92). Para tal, a autora apresenta algumas "perguntas básicas" a serem respondidas. Apesar de não estar se referindo especificamente à relação da Psicologia com o trabalho, é interessante destacá-las, pois parecem também possibilitar a delimitação dos dois enfoques discutidos neste artigo. São elas: "Quais são as origens psicossociais das situações de desigualdade e de opressão?" (p.92); "Como se produzem as mudanças sociais e psicossociais?" (p.93); "Quais são os significados que dão os diferentes atores sociais imersos aos diferentes elementos?" (p.93); "Por que as pessoas que sofrem injustiça e opressão não atuam mais ativamente para transformar a sua situação?" (p.94) e "Como se manifestam as formas de resistência às situações de desigualdade?" (p.94).

Esse tipo de indagação que visa à compreensão das situações de desigualdade e à sua superação não parece ter sentido no âmbito de atuação junto à gestão do trabalho (especialmente em empresas privadas), que tem sido o foco da Psicologia Organizacional ao longo de sua história, pois o poder na 'gestão de pessoas' sustenta-se justamente pela desigualdade e assimetria, ainda que, muitas vezes, associado ao discurso de participação e autonomia (Bernardo, 2009). Por outro lado, essas indagações fazem total sentido para uma Psicologia que parte da crítica ao modelo social de trabalho vigente na atualidade, como tem sido o caso da Psicologia Social do Trabalho.

Assim, a divulgação da ideia de que existe um campo unificado de uma "Psicologia do Trabalho e das Organizações" - incluindo todo tipo de pesquisa e atividade profissional, desde aquelas relacionadas à gestão de pessoas até as que criticam radicalmente os modelos de trabalho no sistema capitalista -, parece servir apenas para borrar as fronteiras entre as diferentes abordagens da Psicologia com relação ao trabalho.

Já a explicitação das diferenças históricas e atuais com relação à Psicologia Organizacional e a Psicologia Social do Trabalho (certamente, há outras), possibilita demarcar as diferenças entre duas perspectivas tão contrastantes desde seus primórdios até a atualidade. Entende-se que essa delimitação não é uma proposta de cisão, visto que, conforme foi apresentado neste artigo, nunca houve uma unicidade entre tais vertentes. Também não cabe realizar julgamentos de valor, classificando uma como melhor do que a outra. Compreende-se que essa diferenciação é importante tão somente para que profissionais e pesquisadores da Psicologia tenham clareza da diversidade de objetos de estudo, referenciais teóricos, propostas metodológicas e posicionamentos políticos que envolvem as pesquisas ou as intervenções relacionadas ao mundo do trabalho e, assim, possam definir com tranquilidade qual caminho querem traçar. 


\section{Colaboradores}

Todos os autores contribuíram na concepção e desenho do estudo, análise de dados e redação final.

\section{Referências}

Associação Brasileira de Psicologia Organizacional e do Trabalho. (2009). Psicologia do trabalho e das organizações: não atuamos pela cisão. Recuperado em janeiro 15, 2012, de http://www.sbpot.org.br/ sbpot2/pdf/ manifesto_psicologia-do-trabalho-eorganizacoes_SBPOT.pdf

Bastos, A. V. B., Yamamoto, O. H., \& Rodrigues, A. C. A. (2013). Compromisso social e ético: desafios para a atuação em psicologia organizacional e do trabalho. In L. O. Borges \& L. Mourão (Orgs.), O trabalho e as organizações: atuações a partir da Psicologia (pp.25-52). Porto Alegre: Artmed.

Bendassolli, P. F., Borges-Andrade, J. E., \& Malvezzi, S. (2010). Paradigmas, eixos temáticos e tensões na PTO no Brasil. Estudos de Psicologia (Natal), 15(3), 281-289.

Bernardo, M. H. (2009). Discurso flexível, trabalho duro: o contraste entre a vivência de trabalhadores e o discurso de gestão empresarial. São Paulo: Expressão Popular.

Bernardo, M. H., Sousa, C. C., Pizón, J. H., \& Souza, H. A. (2015). A práxis da psicologia social do trabalho: reflexões sobre possibilidades de intervenção. In M. C. Coutinho, O. Furtado, \& T. R. Raitz (Orgs.), Psicologia social e trabalho: perspectivas críticas (pp.16-39). Florianópolis: Abrapso.

Borges, L. O., \& Mourão, L. (2013). O trabalho e as organizações: atuações a partir da psicologia. Porto Alegre: Artmed.

Braverman, H. (1987). Trabalho e capital monopolista: a degradação do trabalho no século XX. Rio de Janeiro: Guanabara Koogan.

Carvalho, M. C. R. G. (1981). Fábrica: aspectos psicológicos do trabalho na linha de montagem (Dissertação de mestrado não-publicada). Universidade de São Paulo.

Conselho Federal de Psicologia. (2010). Psicologia crítica do trabalho na sociedade contemporânea. Brasília: Autor.

Farr, R. M. (2004). As raízes da Psicologia social moderna. Petrópolis: Vozes.

Figueiredo, M. A. C. (1989). O trabalho alienado e o psicólogo do trabalho: algumas questões sobre o papel do psicólogo no controle da produção capitalista. São Paulo: Edicon.

Gardiner, M. E. (2000). Critiques of everyday life. London: Routledge.
Huczynski, A. (1993). Management gurus. London: Routledge.

Kuhn, T. S. (1987). A estrutura das revoluções científicas. São Paulo: Perspectiva.

Latour, B., \& Woolgar, S. (1997). A vida de laboratório. Rio de Janeiro: Relume.

Lhuilier, D. (2014). Introdução à psicossociologia do trabalho. Cadernos de Psicologia Social do Trabalho, 17(N. Esp.1), 5-19.

Lima, A. F. (2010). Gênese, desenvolvimento e redefinição da psicologia social: da separação epistemológica ao compromisso com a práxis. Revista Psicologia e Saúde, 2(1), 72-79.

Lima, A. F., Ciampa, A. C., \& Almeida, J. A. M. (2009). A psicologia social como psicologia política? A proposta de psicologia social crítica de Sílvia Lane. Psicologia Política, 9(18), 223-236.

Malvezzi, S. (1999). Psicologia organizacional: da administração científica à globalização, uma história de desafios. In C. G. Machado, M. Melo, V. Franco, \& N. Santos (Orgs.), Interfaces da Psicologia. In Actas do Congresso Internacional "Interfaces da Psicologia" (Vol.2, pp.313-326). Évora: Universidade de Évora.

Mello, S. L. (1988). Trabalho e sobrevivência: mulheres no campo e na periferia. São Paulo: Ática.

Montero, M. (2011). Ser, fazer, parecer: crítica e libertação na América Latina. In R. S. L. Guzzo \& Lacerda Júnior, F. (Orgs.), Psicologia social para América Latina: o resgate da psicologia da libertação. Campinas: Alínea.

Oliveira, F., Esteves, E. G., Bernardo, M. H., \& Sato, L. (2015). Psychologie Sociale du Travail: rencontres entre recherche et intervention. Bulletin de Psychologie, Tome 68(2), 536.

Padilha, V. (2010). Qualidade de vida no trabalho num cenário de precarização: a panaceia delirante. Trabalho, Educação e Saúde, 7(3), 549-563.

Prilleltensky, I. (1994). Morals and politics of Psychology: Psychological discourse and the status quo. Albany: State University of New York.

Rodrigues, A. M. (1978). Operário, operária. São Paulo: Símbolo.

Sampaio, J. R. (1998). A Psicologia do trabalho em três faces. In I. B. Goulart \& J. Sampaio (Orgs.), Psicologia do trabalho e gestão de recursos humanos: estudos contemporâneos. São Paulo: Casa do Psicólogo.

Sato, L. \& Oliveira, F. (1998) Apresentação. Cadernos de Psicologia Social do Trabalho, 1(1), VII-VIII.

Sato, L. (2010). Psicologia, saúde e trabalho: distintas construções dos objetos "trabalho" e "organizações". In Conselho Federal de Psicologia. Psicologia crítica do trabalho na sociedade contemporânea. Brasília: Conselho Federal de Psicologia.

Sato, L., Lacaz, F. A. C., \& Bernardo, M. H. (2006). Psicologia e saúde do trabalhador: práticas e investi- 
gações na Saúde Pública de São Paulo. Estudos de Psicologia (Natal), 11(3), 281-288.

Seligmann-Silva, E. (2011). Trabalho e desgaste mental: o direito de ser dono de si mesmo. Rio de Janeiro: Universidade Federal do Rio de Janeiro.

Silva, N. (2008). A organização como um fenômeno socialmente construído. In J. C. Zanelli \& N. Silva. Interação humana e gestão: a construção psicossocial das organizações de trabalho. São Paulo: Casa do Psicólogo.

Smith, R. (1988). Does the history of psychology have a subject? History of the Human Sciences, 1(2), 147-177.

Spink, P. K. (1996). Organização como fenômeno psicossocial: notas para uma redefinição da psicologia do trabalho. Psicologia \& Sociedade, 8(1), 174-192.
Zanelli, J. C., \& Bastos, A. V. B. (2004). Inserção profissional do psicólogo em organizações e no trabalho. In J. C. Zanelli, J. E. Borges-Andrade, \& A. V. B. Bastos (Orgs.), Psicologia, organizações e trabalho. Porto Alegre: Artmed.

Zanelli, J. C. (2002). O psicólogo nas organizações de trabalho. Porto Alegre: Artmed.

Zanelli, J. C., Borges-Andrade, J. E., \& Bastos, A. V. B. (2007). Psicologia, organizações e trabalho no Brasil. Porto Alegre: Artmed.

Recebido: dezembro 15, 2014

Versão final: julho 16, 2015

Aprovado: outubro 2, 2015 